honeycombed appearance and short spicules. The chorion has a sculpturing that is similar to niveus. The average length of twentyfive eggs that were measured was 2,924 microns and the average width on the broadest portions was 580 microns. The length of the egg caps averaged about 342 microns and the width 447 microns. The eggs of this species differ from those of niveus in that they are more slender and are of a deeper yellow in color, and have shorter spicules on the egg caps. Injuries to raspberry canes by nigricornis are common.

PrRstDent Forbes: Discussion of this paper is now in-order.

Mr. Hopkins: Mr. President, I am especially interested in this paper and am glad to know the species concerned, because it has always been a mystery to me as to what species caused the damage. My observations, however, are that the eggs were deposited almost invariably in pairs and that in a great many cases the canker did not follow the puncture. (Mr. Hopkins then exhibited a plate which he had published in Bulletin 50, West Virginia Agricultural Experiment Station, illustrating the work of tree erickets.)

Mr. Parrotr: I do not want to leave the impression that the cankerous condition was common with all the punctures. This was not the case. It was present, however, with many of the punctures.

Mr. Slingerdand: We have one of our graduate students at Cornell working on this problem and his results are similar to those of Professor Parrott.

President Forbes: Any further discussion? The next paper on the program will be read by Mr. H. E. Summers.

\title{
THE DISTRIBUTION OF SAN JOSE SCALE IN IOWA
}

\author{
By H. E. Summar, Ames, Iowa
}

As the line marking the northwestern limit of injury by the San José scale in the Mississippi Valley passes thru Iowa, the localities in which it has establisht itself in the state seem worthy of record. It has so far been found doing injury only in five counties, namely: Decatur, Lee, Louisa, Mahaska and Linn. Only one center of distribution has been found in each of these localities. Four of these counties are south of the $42 \mathrm{~d}$ parallel; only Linn County being north of it. Four of the outbreaks were in orchards, in all of which some trees were killed. The fifth case was in a nursery in which an isolated block of transplanted trees had been standing for several years, and were found generally infested. Some trees were dying. This block 
had been inspected two years before, but no scale had been found, altho the infection must have then existed, as no trees were after that set in the block and the possibility of infection from surrounding territory seemed to be excluded.

In all the above cases, the scale when discovered was in a thriving condition and it was evident that it was only a question of time, unless treatment were given, when the trees would be entirely destroyed. The Decatur County infection was discovered in the early spring of 1901. It was sprayed with whale oil soap in April of that yoar and with sulfur-lime mixture in the spring of 1902 . Complete eradication of the seale, as was proven by annual inspection for four years afterwards, was the result. The Lee County infection was discovered in May, 1906. It was kept fairly well in check during that summer by two sprayings, with a third upon some trees, with kerosene emulsion. It was sprayed in the spring of 1907 with sulfur-lime mixture. The work was done by the owner and, as inspection soon after showed, the trees had not been entirely covered. By autumn many trees were again badly infested. In the spring of 1908 this orchard was again, and this time carefully, sprayed with lime-sulfur. Inspection this autumn (1908) shows that the treatment was not effective in exterminating, altho the number found on any tree that had been sprayed was very small. One peach tree quite distant from the orchard sprayed, and the only tree on the place that had not been treated, was found this fall to be thickly covered with the scale. This tree had been inspected in the spring and no scale found upon it. It seems evident that the sulfur-lime remained upon the sprayed trees in sufficient amounts during a considerable part of the summer to prevent the establishment and rapid multiplication of the scale. The other two cases of orchard infection have been discovered during the present autumn and no treatment has yet been applied. In the case of the nursery, everything found infected and near the infected stock was cut out and burned; and as this nursery had for two years been establishing itself on new grounds several miles away, it is hoped that complete epadication has been accomplished.

Perhaps greater interest attaches to the question as to how certain Iowa grown nursery trees on which the scale has been found became infested: Several shipments from Iowa have been found by inspectors in other states infested with San José scale. In all but two cases, these trees have been traced back and found to have been shipped into Iowa from nurseries in other states. In two cases, however, the trees were grown in large nurseries in the southwestern part of Iowa far removed from any known infestation. In one case a few scattered 
scales were found on each of three trees out of a lot of nine hundred shipped to Maryland. The other trees were hand inspected and were apparently clean. Six hundred trees, all of the remainder grown in the block, were subsequently hand inspected by me personally at the nursery in Iowa and no scale discovered. In the other case a single tree was found infected in a large shipment made to New York. The question of the source of this scale is a puzzling one. It seems incredible that it should have been introduced on the scions and not have multiplied more in the three years, during which all the infested trees had been growing in the nursery. On the other hand the orchards for at least a mile in every direction from the nursery have been examined with sufficient care to have insured the discovery of any severe infection.

To summarize, the San José scale has twice been found on Iowa grown trees sent out from the nurseries. Once, in a nursery from which it is improbable any infested trees have been sent out, and in four localities, all in the eastern and southern part of the state, in orchards. In three of these it still exists.

Mr. WashBuRN : I shall have to criticize Mr. Summers' statement that Iowa represents the most northern spread of the scale in the Mississippi Valley, because it has been known around Madison, Wisconsin, for two or three years, and in South Dakota I heard this winter that the scale had lived through two winters. The stock was burned up the following summer, so we do not know whether it would have gone through another winter or not. It is rather strange, but we have not found it in Minnesota yet. I have no doubt it is pushing its way north, and we have inoculated, in a muslin cage, out of doors, fruit trees with scales that we have had sent to us, and left the top of the cage open during the winter, and have had scales live through last winter. I don't think we ought to regard Iowa as the most northern limit in the Mississippi Valley. I would like to ask Mr. Summers if he has found it around Charles City.

Mr. Summers: We have never found it anywhere except at the places mentioned in my paper.

President Forbes: If there is no further discussion, the next paper will be presented.

$M r$. Quaintance gave a brief verbal statement of the facts contained in the paper, which follows: 